\title{
Submitted: $\quad$ A blood-mimicking fluid with cholesterol as scatter particles Accepted: for wall-less carotid artery phantom applications
} 01.06 .2021

Published: 16.08.2021

\author{
Keywords \\ blood-mimicking \\ fluid, \\ cholesterol scatter \\ particles, \\ acoustic properties, \\ Doppler ultrasound
}

\author{
Kyermang Kyense Dakok ${ }^{1}$, Mohammed Zubir Matjafri ${ }^{1}$, Nursakinah Suardi ${ }^{1}$, \\ Ammar Anwar Oglat², Seth Ezra Nabasu ${ }^{3}$ \\ ${ }^{1}$ Department of Medical Physics and Radiation Science, School of Physics, Universiti Sains \\ Malaysia, 11800 Penang, Malaysia \\ ${ }^{2}$ Department of Medical Imaging, Faculty of Applied Medical Sciences, The Hashemite \\ University, Zarqa, Jordan \\ ${ }^{3}$ Department of Physics, Plateau State University Bokkos, P.O Box 2012, Plateau Sate, Nigeria \\ Correspondence: Prof. Mohammed Zubir Matjafri,e-mail:mjafri@usm.my
}

DOI: $10.15557 / J o U .2021 .0035$

\begin{abstract}
Aim of the study: At present, there are few scatter particles used in preparing blood-mimicking fluids, such as nylon, sephadex, polystyrene microsphere, and poly(4-methystyrene). In this study, we present cholesterol as a new scatter particle for blood-mimicking fluid preparation. Materials and methods: The procedure for the preparation of the proposed blood-mimicking fluid involved the use of propylene glycol, $\mathrm{D}(+)$-Glucose and distilled water to form a ternary mixture fluid, with cholesterol used as scatter particles. Polyethylene glycol was first used as part of the mixture fluid but the acoustic and physical properties were not suitable, leading to its replacement with $\mathrm{D}(+)$-Glucose, which is soluble in water and has a higher density. A common carotid artery wall-less phantom was also produced to assess the flow properties. Results: The prepared blood-mimicking fluid with new scatter particles has a density of $1.067 \mathrm{~g} / \mathrm{cm}^{3}$, viscosity of $4.1 \mathrm{mPa} . \mathrm{s}$, speed of sound $1600 \mathrm{~m} / \mathrm{s}$, and attenuation of $0.192 \mathrm{~dB} / \mathrm{cm}$ at $5 \mathrm{MHz}$ frequency. Peak systolic velocity, end diastolic velocity and mean velocity measurements were gotten to be $40.2 \pm 2.4 \mathrm{~cm} / \mathrm{s}, 9.9 \pm 1.4 \mathrm{~cm} / \mathrm{s}$, and $24.0 \pm 1.8 \mathrm{~cm} / \mathrm{s}$, respectively. Conclusion: Based on the results obtained, the blood-mimicking fluid was found suitable for ultrasound applications in carotid artery wall-less phantoms because of its good acoustic and physical properties.
\end{abstract}

\section{Introduction}

A blood-mimicking fluid (BMF) is made up of ultrasound scattering particles that stay neutrally buoyant in a fluid. For these particles to be able to remain suspended in the fluid, their density must be very close or equal to the density of the mixture fluid. In addition, the BMF must also have acoustic properties (speed of sound, attenuation and backscatter power) and physical properties (density and viscosity) that are close to the internationally acceptable standard ${ }^{(1-3)}$. The research on BMF started with just water and glycerol as the components of the fluid, mixed with polystyrene microsphere as scatter particles ${ }^{(4,5)}$. Orgasol (nylon) was then introduced as scatter particles, mixed with water, glycerol, dextran, a surfactant and sodium azide $^{(6-12)}$. Other substances that have been used as scatter particles include sephadex ${ }^{(13-16)}$, cellulose pulver ${ }^{(17-18)}$, and hard red blood cells ${ }^{(19)}$.

Real human blood is composed in approximately $55 \%$ of plasma and $45 \%$ of formed elements. The formed elements consist of red blood cells, white blood cells, platelets, and other insoluble substances such as cholesterol; while plasma is made up of about $90 \%$ serum and $10 \%$ other soluble substances including proteins and glucose $\mathrm{e}^{(20,21)}$. Because cholesterol is an insoluble particle in the blood, its movement within blood vessels such as arteries makes it a risk factor for cardiovascular disease known as atherosclerosis or hardening of the artery wall by cholesterol deposits (stenosis) ${ }^{(22)}$. 
Tab. 1. Specifications of the BMF defined as the IEC standard. $f$ is the acoustic frequency $(\mathrm{Hz})(\mathrm{IEC}, 2001)$

\begin{tabular}{|c|c|}
\hline Acoustic and physical properties of BMF & Values \\
\hline Viscosity $\left(\times 10^{-3}\right.$ Pas $)$ & $4.0 \pm 0.4$ \\
\hline Sound speed $(\mathrm{m} / \mathrm{s})$ & $1570 \pm 30$ \\
\hline Attenuation $(\mathrm{dB} / \mathrm{cm} / \mathrm{MHz})$ & $<0.1 \times 10^{-4} \times \mathrm{f}$ \\
\hline Density $\left(\mathrm{g} / \mathrm{cm}^{3}\right)$ & $1050 \pm 40$ \\
\hline
\end{tabular}

In the present study, we prepared a blood-mimicking fluid consisting of water, propylene glycol and glucose as a ternary mixture fluid, with cholesterol serving as the scatter particle. The choice of cholesterol as scatter particles is informed by the knowledge that it is practically insoluble in water and has a density $\left(1.067 \mathrm{~g} / \mathrm{cm}^{3}\right)$ close to the acceptable limit, as seen in Tab. $1^{(1,23)}$. This BMF was used to determine the effect of the presence of cholesterol on in-vitro flow velocity in the common carotid artery wall-less phantom.

\section{Material and methods}

\section{Procedure for preparing BMF}

The BMF mixture fluid was first prepared by varying the percentage compositions of distilled water, propylene glycol (Sigma Aldrich, Germany), and polyethylene glycol (Merck KGaA, 64271 Darmstadt, Germany) in order to find the correct combination that gives an acceptable ternary fluid. The process was carried out as follows:

(i) First, a glass beaker the size about twice the volume of the BMF was washed with distilled water and wiped clean with a tissue paper. The beaker of this size was selected to avoid the overflowing of the fluid while stirring. This was followed by placing a magnetic stirrer inside the beaker.

(ii) $90 \%$ weight/weight $(\mathrm{w} / \mathrm{w})$ of distilled water was measured using a measuring cylinder, and $5 \% \mathrm{w} / \mathrm{w}$ of propylene glycol (PG) was weighed as well as $5 \% \mathrm{w} / \mathrm{w}$ of polyethylene glycol (PEG) in a fume cupboard using an electronic balance (multi-function balance, A\&D Company Ltd, Japan). Distilled water was first poured into the beaker, followed by PG and PEG. The combined components were then placed on a magnetic stirrer hot plate (Favorit, 41200 Klang, Malaysia) for stirring.

(iii) The stirring plate was set to operate at 700 revolutions per minute (rpm) for 20 minutes at a temperature of $37^{\circ} \mathrm{C}$, after which a vacuum pump was used to degas the fluid for about 30 minutes.

(iv) The procedures above were repeated four more times but with different percentages of distilled water and PEG, while the amount of PG remained fixed at 5\% w/w composition. The five (5) samples as well as $100 \% \mathrm{w} / \mathrm{w}$ distilled water were then tested for their densities, viscosities, speed of sound, and attenuation properties. The results are tabulated in Tab. 2.

The serial number 8 in the table has a density $\left(1.065 \mathrm{~g} / \mathrm{cm}^{3}\right)$ close to that of cholesterol. However, it was not suitable as a mixture fluid because the speed of sound $(1670.2 \mathrm{~m} / \mathrm{s}$ ) and viscosity (12.40 mPa.s) diverged considerably from the internationally acceptable values (Tab. 1), even though the attenuation value was within a good range. This led to the replacement of PEG with $\mathrm{D}(+)$-Glucose (DG) (Merck KGaA, Darmstadt, Germany) with a higher density $\left(1.54 \mathrm{~g} / \mathrm{cm}^{3}\right)$, which the steps in (i) to (iv) above were repeated, with the results shown in Tab. 3 .

Tab. 2. Physical and acoustic properties of the mixture fluid for the preparation of a blood-mimicking fluid with propylene glycol and polyethylene glycol at a temperature of $37^{\circ} \mathrm{C}$

\begin{tabular}{|c|c|c|c|c|c|c|c|}
\hline S/No. & $\begin{array}{c}\text { Distilled water } \\
\mathbf{\%}(\mathbf{w} / \mathbf{w})\end{array}$ & $\begin{array}{c}\text { Propylene glycol } \\
\mathbf{\%}(\mathbf{w} / \mathbf{w})\end{array}$ & $\begin{array}{c}\text { Polyethylene glycol } \\
\mathbf{\%}(\mathbf{w} / \mathbf{w})\end{array}$ & $\begin{array}{c}\text { Density } \\
\left(\mathbf{g} / \mathbf{c m}^{\mathbf{3}}\right)\end{array}$ & $\begin{array}{c}\text { Viscosity } \\
(\mathbf{m p a . s})\end{array}$ & $\begin{array}{c}\text { Speed of sound } \\
(\mathbf{m} / \mathbf{s})\end{array}$ & $\begin{array}{c}\text { Attenuation } \\
\mathbf{( d B / c m} / \mathbf{M H z})\end{array}$ \\
\hline 1 & 100 & 0 & 0 & 0.997 & 0.90 & 1506.7 & 0.044 \\
\hline 2 & 90 & 5 & 5 & 1.012 & 2.50 & 1512.1 & 0.050 \\
\hline 4 & 80 & 5 & 15 & 1.031 & 6.80 & 1568.4 & 0.056 \\
\hline 6 & 70 & 5 & 25 & 1.044 & 5.80 & 1692.0 & 0.057 \\
\hline 7 & 60 & 5 & 35 & 1.059 & 10.60 & 1652.5 & 0.059 \\
\hline 8 & 55 & 5 & 40 & 1.065 & 12.40 & 1670.2 & 0.061 \\
\hline 9 & 50 & 5 & 45 & 1.078 & 14.50 & 1696.3 & 0.062 \\
\hline
\end{tabular}

Tab. 3. Physical and acoustic properties of the mixture fluid for the preparation of a blood-mimicking fluid with propylene glycol and $D(+)$-Glucose at a temperature of $37^{\circ} \mathrm{C}$

\begin{tabular}{|c|c|c|c|c|c|c|c|}
\hline S/No. & $\begin{array}{c}\text { Distilled water } \\
\%(w / w)\end{array}$ & $\begin{array}{c}\text { Propylene glycol } \\
\%(w / w)\end{array}$ & $\begin{array}{c}D(+) \text {-Glucose } \\
\%(w / w)\end{array}$ & $\begin{array}{l}\text { Density } \\
\left(\mathrm{g} / \mathrm{cm}^{3}\right)\end{array}$ & $\begin{array}{c}\text { Viscosity } \\
\text { (mpa.s) }\end{array}$ & $\begin{array}{c}\text { Speed of sound } \\
(\mathrm{m} / \mathrm{s})\end{array}$ & $\begin{array}{c}\text { Attenuation } \\
\text { (dB/cm/MHz) }\end{array}$ \\
\hline 1 & 100 & 0 & 0 & 0.993 & 2.8 & 1513.4 & 0.0460 \\
\hline 2 & 90 & 5 & 5 & 1.016 & 3.4 & 1549.3 & 0.0650 \\
\hline 3 & 85 & 5 & 10 & 1.035 & 3.8 & $1566 . .4$ & 0.105 \\
\hline 4 & 80 & 5 & 15 & 1.057 & 4.4 & 1588.4 & 0.190 \\
\hline 5 & 75 & 5 & 20 & 1.079 & 5.2 & 1614.1 & 0.194 \\
\hline 6 & 70 & 5 & 25 & 1.100 & 5.8 & 1634.3 & 0.198 \\
\hline
\end{tabular}




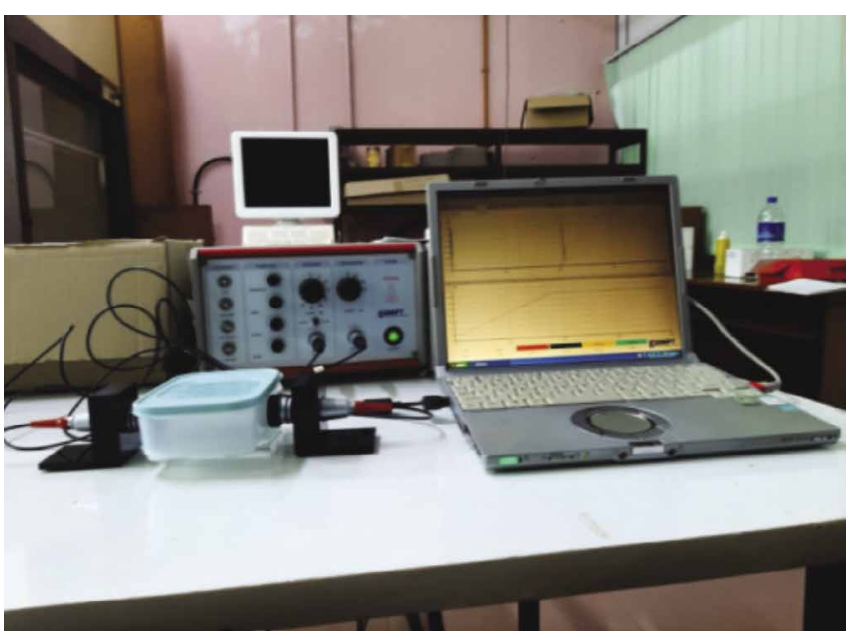

Fig. 1. Measurement of the acoustic properties of solutions using the A-scan GAMPT technique

(v) A linear relationship was established using the statistical package for social sciences (SPSS, Version 21) software between the density and the amount of DG in the fluids, resulting in the equation:

\section{Density $=0.00426($ amount of DG) +0.993}

With equation $1,17.37 \% \mathrm{w} / \mathrm{w}$ of DG by weight was required to mix with $5 \% \mathrm{w} / \mathrm{w}$ of PG and $77.63 \% \mathrm{w} / \mathrm{w}$ of distilled water to produce exactly a mixture fluid with a density of $1.067 \mathrm{~g} / \mathrm{cm}^{3}$, a value required to match the density of cholesterol scatters. This allows the scatter particles to remain neutrally buoyant in the fluid mixture.

(vi) Finally, a sieving net with the mesh size of approximately 10 was used to sieve the cholesterol particles ( $\geq 90 \%$ purified, Merck KGaA Darmstadt, Germany) before mixing them with the fluid. Different concentrations of cholesterol particles were added to the mixture fluid until the right amount required for the particles to stay suspended in the fluid was achieved. The BMF thus prepared was then mixed with about 4 drops $(0.2 \mathrm{ml})$ of benzalkonium chloride (Sigma Aldrich, Germany) solution to serve as a preservative.

\section{Preparation of tissue-mimicking material (TMM) wall-less phantom}

A TMM wall-less phantom of the CCA was prepared with a lumen diameter of $8.0 \mathrm{~mm}$, as described by Ammar et al. ${ }^{(24)}$. The TMM composition was made up of $84 \% \mathrm{w} / \mathrm{w}$ distilled water, $0.53 \% \mathrm{w} / \mathrm{w}$ of silicon carbide (Logitec, Glasgow, UK), $0.96 \%$ w/w of aluminum oxide, $3.0 \mu \mathrm{m}$ size (Sigma Aldrich, Germany), $0.89 \% \mathrm{w} / \mathrm{w}$ of aluminum oxide, $0.3 \mu \mathrm{m}$ size (Sigma Aldrich, Germany), $0.92 \% \mathrm{w} / \mathrm{w}$ of gelatin (gel strength 300, Type A, Sigma Aldrich, Germany), $1.5 \%$ w/w of konjac powder (dietary supplement, NOVA Nutritions, Scotch Plains, New Jersey USA), $1.5 \% \mathrm{w} / \mathrm{w}$ of carrageenan powder (Sigma Aldrich, Germany), $0.7 \%$ w/w of potassium chloride (Sigma Aldrich, Germany), and $9.0 \% \mathrm{w} / \mathrm{w}$ of glycerol
(Vetec $^{\mathrm{TM}}$ reagent grade, Sigma Aldrich, Germany). About $5 \mathrm{~cm}^{3}$ of benzalkonium chloride solution was added to 2 liters of the TMM as an anti-fungal agent. The prepared TMM was cast inside a plastic (acrylic) rectangular box with a straight metal rod placed horizontally inside at a depth of $15 \mathrm{~mm}$. When the TMM had cooled to about $40^{\circ} \mathrm{C}$, the metal rod was removed gradually to provide a lumen which was attached to rubber tubes for connection to a pump.

\section{Measurements of density and viscosity}

The densities of the BMF fluids were measured using a portable density meter (DMA 35, Anton Paar GmbH, Austria) at $37^{\circ} \mathrm{C}$. The strip attached to the meter was pressed down and dipped inside the fluid, and then released to draw up the fluid inside the strip by suction pressure, while the density reading was recorded automatically by the meter in just few seconds.

About $700 \mathrm{~cm}^{3}$ of each BMF was required for the viscosity measurements using the electronic rotational viscometer (ERV) (Software Version 1.2, Fungilab, Barcelona, Spain). The spindle L1 was selected for viscous liquid; it was fixed to the ERV and then lowered into the fluid, while the ERV was switched on. The spindle rotated inside the liquid for a few minutes until a steady value of viscosity was recorded due to the viscous resistance from the fluid ${ }^{(25,26)}$.

\section{Measurements of speed of sound, attenuation and backscatter power}

The speed of sound was measured by the pulse echo (PE) method using the ultrasonic echoscope GAMPT-scan machine (German Society for Applied Medical Physics and Technology, GAMPT Ultrasonic Solutions, Hallesche Straße, Merseburg, Germany). The arrangement for this measurement is shown in (Fig. 1), where the time of flight (TOF) between the highest two peaks of the transmitted and about $90 \%$ of the received signal (energy) at a frequency of $5 \mathrm{MHz}$ was measured. For good accuracy, the protective layer thickness of the probe was first calculated and added to the distance between the walls of the vessel containing the liquid. This was done by using two acrylic plates, $40 \mathrm{~mm}$ and $80 \mathrm{~mm}$ thick, with the same speed of sound of $2700 \mathrm{~m} / \mathrm{s}$. The pulse echo method using A-scan GAMPT technique was able to provide time of flight for the two plates which was used to calculate the thickness of the protective layer of the probe from the equation:

$$
d p_{1}=\frac{\left(\frac{t_{1}}{t_{2}} d a_{2}\right)-d a_{1}}{2\left(1-\begin{array}{c}
t_{1} \\
t_{2}
\end{array}\right)}
$$

where $d p$, is the thickness of the transducer protective layer, $d a_{1}$ is the thickness of the acrylic plate $(40 \mathrm{~mm})$, is the thickness of the acrylic plate $(80 \mathrm{~mm}), t_{1}$ is the time of flight through the plate $(40 \mathrm{~mm})$, and $t_{2}$ is the time 


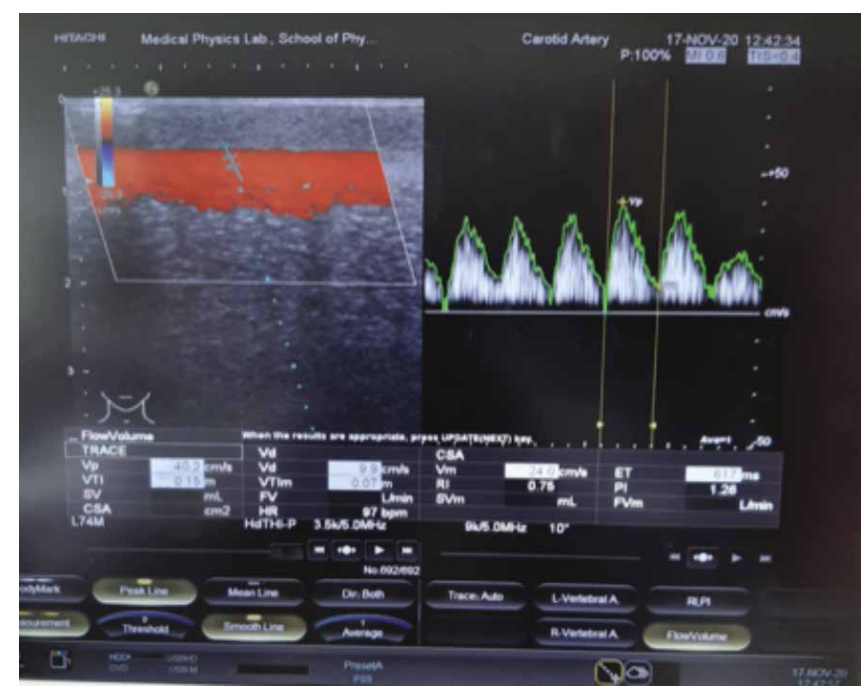

Fig. 2. PW-mode ultrasound measurements of flow indices using the Hitachi Ultrasound Machine

of flight through the plate $(80 \mathrm{~mm})$. The values for the speed of sound for the liquids were calculated from the equation:

$$
\text { speed of sound }=\frac{2 *\left(x+d p_{1}\right)}{t}
$$

where $x$ is the distance between the walls of the vessel containing the mixture liquid and $t$ is the time of flight.

The amplitudes of the highest two similar peaks were also measured, and the attenuation coefficients $(\alpha)$ were calculated from the attenuation equation:

$$
a=\frac{2 \times 0.868}{x} \ln \frac{A_{2}}{A_{1}}
$$

where $A_{1}$ and $A_{2}$ are the amplitudes of the two highest but similar wave peaks, respectively, and $x$ is the distance.

The backscatter power of the BMF was measured at different radio-frequency signals by calculating the average power spectrum through applying the fast Fourier transform (FFT) generated by the A-scan GAMPT at $5 \mathrm{MHz}$. This was done to find out if the BMF simulates real human blood.

\section{Doppler ultrasound measurement of flow velocities}

A digital clinical Hitachi ultrasound scanning machine (HI VISION Avius, Hitachi Medical Corporation, Tokyo, Japan) connected to a linear array transducer (probe) EUP-L74M with frequencies ranging from 5 to $13 \mathrm{MHz}$ was used to obtain an image of the wall-less flow phantom. The phantom was placed on a flat table and connected to a centrifugal multi-flow pump (German Society for Applied Medical Physics and Technology, GAMPT $\mathrm{mbH}$, Hallesche Straße, Merseburg, Germany) with the aid of plastic tubes to pump the BMF. The fluid was pumped through the lumen at a flow rate of $1500 \mathrm{ml} / \mathrm{min}$ (for both steady and pulsed flow), and B-mode images of the lumen and the BMF were displayed on the screen of the scanning machine. The measurements of peak systolic velocity (PSV), end-diastolic velocity (EDV), mean or average velocity $\left(\mathrm{V}_{\mathrm{m}}\right)$, pulsatility index $(\mathrm{PI})$ and resistivity index were carried out by color Doppler and pulsed-wave (PW) Doppler systems. The angle of beam (insonation angle) was set at the center of the flow at $60^{\circ}$ with the required sample volume and entrance length of about 8 $\mathrm{cm}$. To obtain a good image of the phantom and BMF flow, the transmitting frequency was adjusted on the scanner and set at $5 \mathrm{MHz}$, while the display depth, focus position, image size, sample gate, pulse repetition frequency (PRF), sample volume and color brightness settings were all adjusted until the normal settings were achieved.

\section{Results}

The results obtained when a fixed percentage composition of PG $(5 \% \mathrm{w} / \mathrm{w})$ was combined with different percentages of PEG and distilled water can be seen in Tab. 2. A second trial of the same procedure with DG also showed a linear relationship between DG with the physical and acoustic properties (Tab. 3). This mixture fluid produced a BMF with $0.7 \%$ of cholesterol as scatter particles, viscosity of $4.1 \pm 0.04 \mathrm{mPa} . \mathrm{s}$, speed of sound $1600 \pm 2 \mathrm{~m} / \mathrm{s}$, and attenuation of $0.192 \pm 0.0002 \mathrm{~dB} / \mathrm{cm}$ at $5.0 \mathrm{MHz}$. The results of velocity measurements (Fig. 2) at a flow rate of $1500 \mathrm{ml} / \mathrm{min}$ through the wall-less lumen of the phantom revealed that the PSV, EDV and the $\mathrm{V}_{\mathrm{m}}$ were $(40.2 \pm 2.4 \mathrm{~cm} / \mathrm{s}$, $9.9 \pm 1.4 \mathrm{~cm} / \mathrm{s}$, and $24.0 \pm 1.8 \mathrm{~cm} / \mathrm{s}$, respectively). The \pm sign values attached to the physical and acoustic measurements represent the estimated standard deviation values.

The measured attenuation, $a(\mathrm{~dB} / \mathrm{cm})$, was found to vary with frequency, $f(\mathrm{MHz})$, as $0.08 f-0.00832 f^{2}$. Using this polynomial, the value of the attenuation at a frequency of $5 \mathrm{MHz}$ was estimated to be $0.192 \mathrm{~dB} / \mathrm{cm}$.

\section{Discussion}

The amount of PG was fixed because its density $(1.036 \mathrm{~g} /$ $\left.\mathrm{cm}^{3}\right)$ is lower than that of PEG $\left(1.124 \mathrm{~g} / \mathrm{cm}^{3}\right)$, but greater than that of water $\left(0.998 \mathrm{~g} / \mathrm{cm}^{3}\right)$. Therefore, increasing the amount of PG alongside those of water and PEG resulted in decreasing the density of the resulting mixture fluid. Increasing the amount of PEG while decreasing that of water led to increases in the values of density, viscosity, speed of sound, and attenuation. This result could not be considered suitable for selection because the combinations required to produce a density equal or close to that of cholesterol $\left(1.067 \mathrm{~g} / \mathrm{cm}^{3}\right)$ had higher values for speed of sound and viscosity even though attenuation was within an acceptable range. The need to replace PEG with a substance of higher density led to the introduction of DG with a density of $1.50 \mathrm{~g} / \mathrm{cm}^{3}$, with another advantage of being soluble in water.

To obtain the exact percentage combination which yielded the same density with the cholesterol scatter particles, 


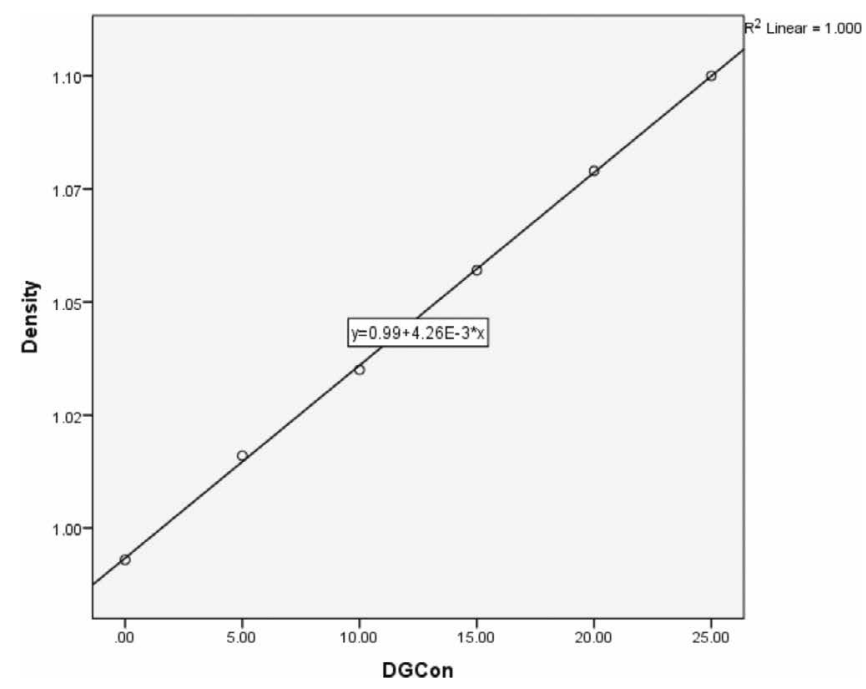

Fig. 3. Linear graphical representation of the relationship between density and d(+)-glucose

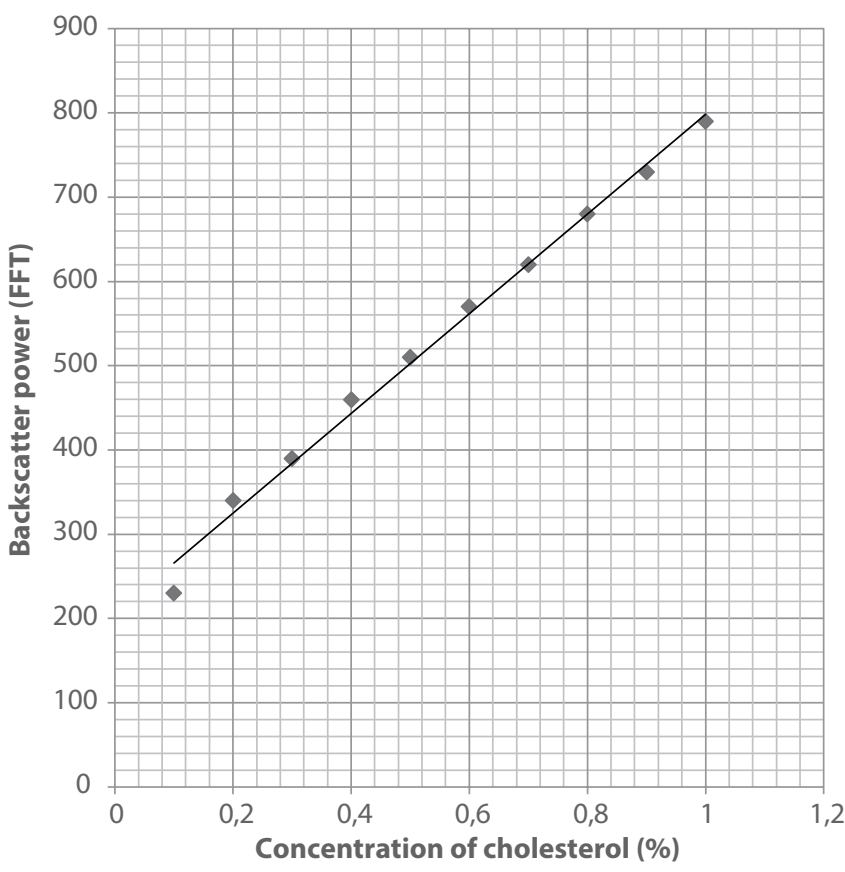

Fig. 4. Backscatter power as a function of particle (cholesterol) concentration, displaying linear response of the FFT by (GAMPT) ultrasonic backscatter measurement

a mathematical equation from the linear relationship (Fig. 3) between percentage DG and density was established (equation 1). The use of equation 1 resulted in a ternary mixture fluid prepared by combining $77.63 \% \mathrm{w} / \mathrm{w}$ distilled water, $5 \% \mathrm{w} / \mathrm{w}$ PG, and $17.37 \% \mathrm{w} / \mathrm{w}$ DG with a density of $1.067 \mathrm{~g} / \mathrm{cm}^{3}$. With these properties, the BMF is suitable for use in Doppler ultrasound pre-clinical applications and studies. The backscatter measurement of the BMF at different percentage concentrations of cholesterol showed that backscatter increased with an increase in the particle ratio (Fig. 4) ${ }^{(2,27)}$. Cholesterol scatter lowers the flow velocity of the BMF within the arteries when compared with normal standards, which requires more pressure from the pump to achieve the required volume flow to the desired organs. The high pressure makes these cholesterol particles have more contact with the walls of the artery, thereby attaching them to the walls, which leads to the formation of plaques (atherosclerosis) in the real human artery ${ }^{(22,28)}$. The PI and RI values for the BMF flow are within the normal range of $20 \mathrm{~cm} / \mathrm{s}$ to $32 \mathrm{~cm} / \mathrm{s}$ for EDV, 0.98 to 1.94 for PI, and 0.72 to 0.84 for $\mathrm{RI})^{(3)}$.

\section{Conclusion}

In this study, we introduced a new scatter particle (cholesterol) to prepare a BMF with acceptable acoustic and physical properties. The BMF is made up of $77.63 \%$ distilled water, $5 \%$ PG, $17.37 \%$ DG, and $0.7 \%$ cholesterol as scatter particles. It has acceptable backscatter properties and hemodynamic parameters; therefore, it is recommended for use in ultrasound phantom applications and research studies.

\section{Acknowledgment}

This research study was supported by Prof. Dr. Mohammad Zubir Mat Jafri and Dr. Nursakinah Suardi under the grant numbers 1001/ PFIZIK/822173 (Universiti Sains Malaysia Incentive grant) and 1001/ PFIZIK/8011111(RUI grant), respectively. We thank our colleagues from Universiti Sains Malaysia, Medical Physics and Radiation Science department, who provided insight and expertise that made this study possible.

\section{Financial support and sponsorship}

This study did not receive any specific grant from any funding agencies in the public, commercial, or non-for-profit sectors.

\section{Conflict of interest}

There are no conflicts of interest.

\section{Author contribution statement}

This research study was supported by Prof. Dr. M.Z.J. and Dr N.S. under the grant numbers 1001/PFIZIK/822173 (Universiti Sains Malaysia Incentive grant) and 1001/PFIZIK/8011111(RUI grant), respectively. Dr A.A.O. proof read and gave technical advice, MrS. E. N contributed with relevant information concerning the content of the paper, and $\mathrm{Mr}$ D.K.K compiled the manuscript. 


\section{References}

1. International Electrotechnical Commission: Ultrasonics - Flow measurement systems - Flow test object. International Standard 2001: 61685.

2. Oglat AA, Matjafri MZ, Suardi N, Oglat MA, Oqlat AA, Abdelrahman MA: A new blood mimicking fluid using propylene glycol and their properties for a flow phantom test of medical Doppler ultrasound. Int J Chem 2017; 5: 220-231.

3. Oglat AA, Matjafri MZ, Suardi N, Oglat MA, Abdelrahman MA, Oqlat AA: Review of medical Doppler ultrasonography of blood flow in general and especially in common carotid artery. J Med Ultrasound 2018; 26: 3-13.

4. Boote EJ, Zagzebski JA: Performance tests of Doppler ultrasound equipment with a tissue and blood-mimicking phantom. J Ultrasound Med 1988; 7: 137-147.

5. Kimme-Smith C, Hussain R, Duerinckx A, Tessler F, Grant E: Medical of Duplex of consistent with a variety Doppler. Radiology 1990; 177: 265-272.

6. Oates CP: Towards an ideal blood analogue for Doppler ultrasound phantoms. Phys Med Biol 1991; 36: 1433-1442.

7. Rickey DW, Picot PA, Christopher DA, FensterA: A wall-less vessel phantom for Doppler ultrasound studies. Ultrasound Med Biol 1995; 21: 1163-1176.

8. Ramnarine KV, Nassiri DK, Hoskins PR, Lubbers J: Validation of a new blood-mimicking fluid for use in Doppler flow test objects. Ultrasound Med Biol 1998; 24: 451-459.

9. Lubbers J: Application of a new blood-mimicking Doppler test object. Eur J Ultrasound 1999; 9: 267-276.

10. Ramnarine KU, Hoskins PE, Routh HE, Davidson FA: Doppler backscatter properties of a blood-mimicking fluid for Doppler performance assessment. Ultrasound Med Biol 1999; 25: 105-110.

11. Samavat H, Evans JA: An ideal blood mimicking fluid for doppler ultrasound phantoms. J Med Phys 2006; 31: 275-278.

12. Yousif MY, Holdsworth DW, Poepping TL: Deriving a blood-mimicking fluid for particle image velocimetry in sylgard-184 vascular models. Annu Int Conf IEEE Eng Med Biol Soc 2009: 1412-1415.

13. Douville Y, Johnston KW, Kassam M, Zuech P, Cobbold RS, Jares A: An in-vitro model and its application for the study of carotid Doppler spectral broadening. Ultrasound Med Biol 1983; 9: 347-356.

14. Hein IA, O'Brien WD: A flexible blood flow phantom capable of independently producing constant and pulsatile flow with a predictable spatial flow profile for ultrasound flow measurement validations. IEEE Trans Biomed Eng 1992; 37: 1111-1122.
15. Hoskins PR, Anderson T, McDicken WN: A computer controlled flow phantom for generation of physiological Doppler waveforms. Phys Med Biol 1989; 34: 1709-1717.

16. Hoskins PR, Loupas T, McDicken WN: Comparison of the Doppler from human blood and artificial blood used in a flow phantom. Ultrasound Med Biol 1990; 16: 141-147.

17. Newhouse VL, Nathan RS, Hertzler LW: Proposed standard target for ultrasound Doppler gain calibration. Ultrasound Med Biol 1982; 8: 313-316.

18. Holdsworth DW, Rickey DW, Drangova M, Miller DJ, Fenster A: Computer-controlled positive displacement pump for physiologial flow simulation. Med Biol Eng Comput 1991; 29: 565-570.

19. Law YF, Johnston KW, Routh HF, Cobbold RS: On the design and evaluation of a steady flow model for Doppler ultrasound studies. Ultrasound Med Biol 1988; 15: 505-516.

20. Waite L, Fine J: Applied Biofluid Mechanics. McGraw-Hill Education, New York 2007.

21. Petersson K: Clinical applications of acoustophoresis in blood based diagnostics. Lund University, Department of Biomedical Engineering 2018.

22. Vasudevan DM, Sreekumari S, Kannan V: Textbook of Biochemistry for Medical Students. 7th ed. JP Medical Publishers, Philadelphia 2013.

23. Zhou X, Kenwright DA, Wang S, Hossack JA, Hoskins PR: Fabrication of two flow phantoms for doppler ultrasound imaging. IEEE Trans Ultrason Ferroelectr Freq Control 2017; 64: 53-65.

24. Oglat AA, Matjafri MZ, Suardi N, Oqlat MA, Oqlat AA, Abdelrahman MA et al.: Characterization and construction of a robust and elastic wallless flow phantom for high pressure flow rate using Doppler ultrasound applications. Natur Engin Sci 2018; 3: 359-377.

25. Kim YR, Moon KY, Cho NC, Kweon EY, Lee DW: Measuring blood viscosity in normal tension glaucoma patients. J Korean Ophthalmol Soc 2015; 56: 753-758.

26. Chunhwa I, Lee D-S, Kyung HA, Ju SO: Viscosity measurement of whole blood with parallel plate rheometers. BioChip J 2020; 14: 179-148.

27. Oglat A, Suardi N, Matjafri MZ, Oqlat MA, Abdelrahman MA, Oqlat AA: A review of suspension-scattered particles used in blood-mimicking fluid for doppler ultrasound imaging. J Med Ultrasound 2018; 26: 68-76.

28. Virani SS, Catellier DJ, Pompeii LA, Nambi V, Hoogeveen RC, Wasserman BA et al.: Relation of cholesterol and lipoprotein parameters with carotid artery plaque characteristics: the Atherosclerosis Risk in Communities (ARIC) carotid MRI study. Atherosclerosis 2011; 19: 596-602. 